\title{
Determining the optimal blood flow restriction protocol for maximising muscle hypertrophy and strength, pressure and cuff width: A mini-review
}

\author{
TORE CHRISTIAN NÆESS \\ Department of Physical Performance, Norwegian School of Sport Sciences, Oslo, Norway
}

\begin{abstract}
Low load resistance training accompanied by blood flow restriction (BFR) has been established as a training modality to induce hypertrophy and strength adaptations. Throughout the BFR-literature, several protocols have emerged with a vast difference among manipulations regarding limb occlusion pressure and the use of different cuff sizes. The aim of this review is to summarise the research underpinning the stimulus regarding alterations in occlusion pressure and the use of different cuff widths, thus investigate whether an optimal protocol is evident. While the focal point of BFR-literature supports the efficiency of several BFR-protocols, no uniform BFR-protocol are located in the literature to maximise muscle hypertrophy and strength. However, an optimal limb occlusion pressure is crucial to achieve venous blood pooling, thus induce a significant stimulus to the muscle, and should be individualised and likely applied relative to the maximum arterial occlusion pressure. Quantification of the optimal pressure range is currently a disputed topic, with no conclusive evidence leading to the most efficient range of applied pressure. Regarding cuff widths, applying an absolute or relative pressure, and their implications regarding the hemodynamics of blood flow should be considered by the researchers. The author would highlight that future BFR studies should be conducted to shed light on the determinants underpinning the protocol to optimise muscle hypertrophy and strength through BFR resistance training, which could have an important ramification through its increasing use in clinical settings and athletic development.
\end{abstract}

Keywords: Blood flow restriction; Cuff width; Hypertrophy; Occlusion pressure.

Cite this article as:

Næss, T.C. (2021). Determining the optimal blood flow restriction protocol for maximising muscle hypertrophy and strength, pressure and cuff width: A mini-review. Journal of Human Sport and Exercise, 16(4), 752-759. https://doi.org/10.14198/hhse.2021.164.02

Corresponding author. Department of Physical Performance, Norwegian School of Sport Sciences, Oslo, Norway. https://orcid.org/0000-0001-5959-6118

E-mail: tore.christian.93@gmail.com

Submitted for publication February 29, 2020.

Accepted for publication May 04, 2020.

Published October 01, 2021 (in press May 13, 2020)

JOURNAL OF HUMAN SPORT \& EXERCISE ISSN 1988-5202

(c) Faculty of Education. University of Alicante.

doi:10.14198/jhse.2021.164.02 


\section{INTRODUCTION}

Blood flow restriction (BFR) resistance training has been established as a training modality to induce significant skeletal muscle hypertrophy and augment force production capacity (Slysz, Stultz, \& Burr, 2016). It was originally thought that a high load of mechanical resistance (> $70 \%$ of $1 \mathrm{RM}$ ) was needed to induce these adaptations in the muscle. However, emerging evidence support the notion that a lower mechanical resistance $(10-40 \%$ of $1 \mathrm{RM})$ accompanied by blood flow restriction has the potential to promote similar hypertrophic adaptations (Kim et al., 2017; Laurentino et al., 2012; Lixandrao et al., 2018; Vechin et al., 2015). From a sports performance aspect, combining blood flow restriction with different training modalities has been demonstrated to increase running economy and time to exhaustion with running exercise (Paton, Addis, \& Taylor, 2017); increase $100 \mathrm{~m}$ running-speed in combination with sprinting (Behringer, Behlau, Montag, McCourt, \& Mester, 2017); enhance aerobic capacity (Abe et al., 2010), and maximal power output and delayed onset of blood lactate accumulation with cycling intervals (de Oliveira, Caputo, Corvino, \& Denadai, 2016).

In addition to the sports performance aspects related to BFR-training, health parameters and rehabilitation training after injury should be considered. Since the quality and the quantity of the skeletal muscle mass is important to maintain healthy function and to carry out daily activities, the elderly population should participate in regular resistance training to countermeasure some of the atrophy and loss of strength accompanied by aging (Goodpaster et al., 2006). However, some of the elderly populations are frail and unable to perform traditional heavy resistance training using mechanical loads above $70 \%$ of maximum force capacity. Thus, blood flow restriction resistance training seems to be an effective training method to induce similar strength and hypertrophy adaptations to the elderly population while inducing a hypotensive effect to the same magnitude compared to traditional heavy resistance training (Cook, LaRoche, Villa, Barile, \& Manini, 2017; Vechin et al., 2015). Considering the aspect of rehabilitation after different injuries, high mechanical loads are often bypassed, thus the resistance training for muscle hypertrophy and strength are compromised. However, blood flow restriction exercise has been demonstrated to be an efficient method for achilles tendon rupture rehabilitation (Yow, Tennent, Dowd, Loenneke, \& Owens, 2018) and to increase peak torque, power output and restore strength after extremity injury (Hylden, Burns, Stinner, \& Owens, 2015).

To conduct this review, a methodical search strategy was employed to pinpoint and establish relevant scientific citations from the earliest record up to June 2019. Key terms used in the searching process includes: "occlusion training", "blood flow restriction training", "blood flow restriction protocols", "practical blood flow restriction training" and "Kaatsu training". The search was limited to English language citations and papers were only considered if the study was conducted on human test subjects. Admissible articles were retrieved from the National Library of Medicine database (PubMed), Google Scholar, Web of Science and through evaluating the reference lists from significant scientific contributions to the field of BFR-training.

In the subsequent sections, the author will first briefly review some of the BFR-protocols used in the literature, then further discuss thoroughly two important aspects related to the BFR-protocol: Applied occlusion pressure and cuff width. The implications of different manipulations in relation to these two factors will be evaluated in an effort to investigate the variables that could optimise the training stimulus to enhance muscle hypertrophy and strength. Thus, the primary aim of this paper is to investigate whether an optimal BFRprotocol to increase muscle mass and strength is evident, while the secondary aim is to review the BFRliterature regarding manipulations in occlusion pressure and cuff width. 


\section{BFR-PROTOCOL: OVERVIEW}

An abundant amount of manipulations and alterations can be rendered to create a BFR-resistance training protocol to induce hypertrophy and strength. The main determinants that underpin these adaptations in regard to the BFR-protocol is: Training load, exercise volume, applied limb pressure, continuously/intermittent occlusion, cuff size, inter-set recovery and whether taking the set to failure or the use a predefined submaximal amount of repetitions. Among the BFR-literature, mounting evidence support the effectiveness of several protocols to induce muscular adaptations (Table 1). For instance, Martin-Hernandez and colleagues (2013) used 30-15-15-15 rep with 20\% of 1RM using continuously blood flow restriction with an absolute pressure at $110 \mathrm{mmHg}$ with a $140 \mathrm{~mm}$ cuff, while Clark and colleagues (2011) used 3 sets to concentric failure with $30 \%$ of $1 \mathrm{RM}$ using continuously blood flow restriction inflated to $130 \%$ above the resting brachial systolic blood pressure with a $60 \mathrm{~mm}$ cuff. These studies demonstrate different alterations regarding important factors underpinning the stimulus to the muscle, hence the muscular adaptations of several training sessions performed consequently. Besides the two diverse BFR-protocols in the studies above, similar strength adaptations were attained in response to $10-12$ sessions (6-8\% increase in muscle strength).

Table 1. A summary of BFR-resistance training studies showing the discrepancies in several important determinants underpinning the applied stimulus of a BFR-training session. Note the large variations among cuff width and pressure.

\begin{tabular}{lllll}
\hline Study & Cuff width (cm) & Pressure & Training load (\%1RM) & Volume (set x rep) \\
\hline Barnett et al., 2016 & unknown & $40 \% \mathrm{AOP}$ & 30 & $30,15,15,15$ \\
Clark et al., 2011 & 6 & $130 \%$ resting SBP & 30 & $3 \times$ failure \\
Cook et al., 2017 & 6 & $150 \%$ resting SBP & 30 & 3 x failure \\
Dankel et al., 2017 & 3 & $160 \mathrm{mmHg}$ & unknown & $4 \times$ failure \\
Dankel et al., 2017 & 5 & $40 \% \mathrm{AOP}$ & unknown & $4 \times$ failure \\
Drummond et al., 2008 & unknown & $200 \mathrm{mmHg}$ & 20 & $30,15,15,15$ \\
Ferguson et al., 2018 & 13 & $110 \mathrm{mmHg}$ & 20 & $30,15,15$, failure \\
Freitas et al., 2017 & 5 & $160 \mathrm{mmHg}$ & 20 & $30,15,15,15$ \\
Fry et al., 2010 & unknown & $200 \mathrm{mmHg}$ & 20 & $30,15,15,15$ \\
Iversen et al., 2010 & 14 & $100 \mathrm{mmHg}$ & unknown & $30,15,15,15,15$ \\
Jessee et al., 2018 & 5 & $40 \% \mathrm{AOP}$ & 30 and 50 & $4 \times$ failure \\
Laurentino et al., 2012 & 17.5 & $80 \% \mathrm{AOP}$ & 20 & $3 \times 15$ \\
Laurentino et al., 2016 & 5 and 10 & $80 \% \mathrm{AOP}$ & 20 & $3 \times 15$ \\
Lixandrao et al.,, 2015 & unknown & $40 \%$ and $80 \%$ & 20 and 40 & $2-3 \times 15$ \\
Loenneke et al., 2015 & 5 & $40 \%, 50 \%$ and $60 \%$ & 20 and 30 & $30,15,15,15$ \\
Madarame et al., 2008 & 4 & $160 \mathrm{mmHg}$ & 30 & $30,15,15$ \\
Manini et al., 2012 & 11 & $150 \% \mathrm{resting} \mathrm{SBP}$ & 20 & $4 \times$ failure \\
Martin-Hernandez et al., 2013 & 14 & $110 \mathrm{mmHg}$ & 20 & $30,15,15,15$ \\
Neto et al., 2015 & 6 and 10 & $80 \% \mathrm{AOP}$ & 20 & $30,15,15,15$ \\
Nielsen et al., 2017 & 13.5 & $100 \mathrm{mmHg}$ & 20 & $4 \times$ failure \\
Sousa et al., 2017 & 18 & $80 \% \mathrm{AOP}$ & 30 & $4 \times$ failure \\
Souza et al., 2018 & 18 & $50 \% \mathrm{AOP}$ & 20 & $30,15,15,15$ \\
Suga et al., 2009 & 18.5 & $130 \%$ resting SBP & 20 & $2 \times 30$ \\
Vechin et al., 2015 & 18 & $50 \% \mathrm{AOP}$ & 20 & $30,15,15,15$ \\
Wernbom et al., 2013 & 13.5 & $90-100 \mathrm{mmHg}$ & 30 & $5 \times$ failure \\
Yow et al., 2018 & 14 & $80 \% \mathrm{AOP}$ & 30 & $30,15,15,15$ \\
\hline
\end{tabular}


Table 1 summarises several different protocols among the BFR-resistance exercise studies. Note the large variation in pressure and cuff width along with the different exercise intensity and volume utilised by different researchers. With the large discrepancy of the BFR-protocols among the literature, direct comparisons between studies are hampered. However, some BFR-protocols appears more often $(30,15,15,15$ \& 3 x failure), despite the use of different cuff widths and different methods to apply occlusion pressure among these protocols. Hence, to the author's knowledge, no common unity regarding the optimal BFR-protocol appear evident in the current revised BFR-literature with respect to increases in strength and hypertrophy.

\section{BFR-PROTOCOL: PRESSURE}

A distinctive feature of blood flow restriction is determining the degree of pressure applied to the extremity. Pressure could be measured with a sphygmomanometer consisting of an inflatable cuff and a measuring unit, e.g., a mercury manometer. An absolute pressure in $\mathrm{X} \mathrm{mmHg}$ could then be applied to the limb, used in several investigations seen from Table 1 . The range of absolute pressure among these investigations vary greatly, $40-200 \mathrm{mmHg}$, in other terms, the largest value of pressure applied is fivefold the lowest pressure. This can have direct implications of the magnitude and the variations of the stimulus induced by the resistance training of different subjects and increase the risk for some subjects to be placed under complete arterial occlusion (Dankel, Buckner, et al., 2017). It is speculated that the quantity of pressure follows a dose responsive manner as the hormesis curve (Loenneke, Thiebaud, Abe, \& Bemben, 2014). If so, an optimal pressure gradient will inhibit venous blood flow while reducing the arterial inflow of blood, thus a blood pooling will be evident in the muscle tissue (Lida et al., 2007).

Another way to assess limb pressure while minimising the potential errors associated with an absolute value of $\mathrm{X} \mathrm{mmHg}$, is to apply the pressure relative to the arterial occlusion pressure (AOP). AOP is often defined as the least amount of pressure required for a complete reduction in arterial blood flow, which could be measured with the use of ultrasound. Several blood flow restriction investigations have used this method to assess relative pressure for their test-subjects (Table 1). The range of relative pressure across these investigations cover $40-90 \%$ of AOP.

A study conducted by Lixandrão and colleagues (2015) was carried out to explore muscle hypertrophy and strength comparing 40 and $80 \%$ of AOP in response to 12 weeks of resistance training with blood flow restriction using two different training intensities of 20 and $40 \%$ of 1 RM. Regarding muscle mass, increasing pressure from 40 to $80 \%$ when training with $20 \%$ of 1 RM, resulted in a larger muscle mass by $2.44 \%$. However, when exercising at $40 \%$ of $1 \mathrm{RM}$, a larger pressure did not result in any meaningful improvements in either strength or hypertrophy (Lixandrao et al., 2015). These results are reproduced by Dankel and colleagues (2017) showing that occlusion protocols utilising a low training load (10-20\% of 1RM), benefits from increased blood flow restriction pressures. Thus, an increase in AOP could elicit in a meaningful muscular adaptation when the BFR-protocol utilise a training load at the lower range.

A recent study by Mouser and colleagues (2017) studied the hemodynamics of blood flow at different pressures (rest-100\% of AOP). One interesting finding was that the blood flow was relatively unchanged between 50 and $90 \%$ of the arterial occlusion pressure, thus the blood flow reduced in a non-linear fashion with the increasing pressure. It is also documented that a larger percentage of AOP is accompanied by increased perceptual responses such as discomfort and increased rating of perceived exertion leading to a decrease in exercise volume compared to lower restriction pressures (Mattocks et al., 2017). Another group of researchers studied the muscle adaptations in response to 8 weeks of BFR-training with the use of $40 \%$ of AOP and $90 \%$ of AOP applied to the same cuff (unknown width) (Counts et al., 2016). Both training 
protocols induced muscle hypertrophy, enhanced peak isotonic strength and muscular endurance with no significant differences between the two protocols. A secondary recent study indicate that arterial occlusion pressure as low as $50 \%$ can induce similar hypertrophy and strength increases compared to traditional heavy resistance training (Kim et al., 2017).

Despite the literature of pressure regarding blood flow restriction training, an optimal pressure is yet to be confirmed, and the existing methods are likely to be imperfect. However, based on the studies above, it could be more conservative to select a lower relative pressure to; (a) reduce the probability of prolonged exposure to ischemia (associated with skeletal muscle damage); (b) more likely able to achieve a sufficient training volume; (c) reduce unnecessary discomfort for the subjects, and (d) reduce dropout rate of participants. In addition, BFR-pressure should be considered in relation to the width of the cuff.

\section{BFR-PROTOCOL: CUFF WIDTH}

Reviewing the literature reveals that a broad range of different cuff widths $(30-185 \mathrm{~mm})$ are commonly applied among the blood flow restriction investigations (Table 1). An important aspect regarding cuff width is the amount of applied pressure required to achieve a venous blood pooling without a complete arterial occlusion, which is suggested as an important stimulus to induce muscle hypertrophy associated with muscle swelling (Loenneke, Fahs, Thiebaud, et al., 2012). Jessee and colleagues (2016) studied 249 subjects in relation to three commonly used cuff widths $(50,100$ and $120 \mathrm{~mm})$ in response to the pressure required for complete AOP. An interesting finding was that the narrow cuff $(50 \mathrm{~mm})$ required the greatest pressure to occlude blood flow followed by the larger cuff $(100 \mathrm{~mm})$ while the largest cuff $(120 \mathrm{~mm})$ required the least pressure. Quantification data from another investigation supports that narrow cuffs $(50 \mathrm{~mm})$ compared to larger cuffs $(135 \mathrm{~mm})$, requires greater $(61 \%)$ absolute pressure to induce complete arterial occlusion $(235 \mathrm{mmHg}$ vs. $144 \mathrm{mmHg}$, respectively)(Loenneke, Fahs, Rossow, et al., 2012). This relationship is evident in several investigations (Crenshaw, Hargens, Gershuni, \& Rydevik, 1988; Graham, Breault, McEwen, \& McGraw, 1993; Loenneke, Fahs, Rossow, et al., 2012). It is therefore proposed that the absolute pressure should be applied in relation to the width of the cuff. However, a recent study conducted by Mouser and colleagues (2018), examined the acute hemodynamic responses to the commonly applied $100 \mathrm{~mm}$ - and the $120 \mathrm{~mm}$ cuff. A noteworthy result from this investigation, revealed that when a relative equal pressure was applied to the cuffs, there were no significant differences among blood flow, mean blood velocity, peak blood velocity and artery diameter. This indicates that the $100 \mathrm{~mm}$ and the $120 \mathrm{~mm}$ cuff apply an equivalent blood flow stimulus when using equal relative AOP. Supporting this assertion is results from another study comparing 50,100 and $120 \mathrm{~mm}$ cuffs applying 40 to $90 \%$ of AOP, showing that relative pressures appear to elicit similar blood flow responses, despite different cuff widths (Mouser et al., 2017).

The studies above are more concerned with pressure regulations and the acute responses to hemodynamic variables associated with the applied stimulus of a BFR-protocol. A further relevant aspect regards the physiological adaptations when frequent training sessions are performed with BFR-training with a narrow compared to a wider cuff. It is speculated that a narrower cuff should theoretically compress less muscle tissue, thus it is plausible to theorise that a narrower cuff is more efficient in increasing muscle growth. This question was addressed by Laurentino and colleagues (2016), studying the cross sectional area (CSA) and maximum strength of the elbow flexors in response to 6 weeks of either BFR-training with narrow cuffs (50 $\mathrm{mm}$ ) or BFR-training with wider cuffs $(100 \mathrm{~mm})$. To equalise the BFR-training stimulus of both groups, a relative pressure at $80 \%$ of AOP was applied with an equivalent training volume. Both BFR-protocols resulted in increased CSA $(\approx 10 \%)$ and strength $(\approx 12 \%)$. Despite the differences of cuff widths, no significant changes were identified regarding changes in elbow flexors CSA $(p=.97)$ and muscle strength measured in 1RM ( $p$ 
$=.96$ ) between the narrow and wide cuff protocol. In defiance of the accumulated evidence supporting the efficiency of BFR-resistance training, little is currently known about the long term BFR-training adaptations to different cuff widths. It is therefore too ambiguous for the author to give a direct answer in this short review on the paramount question: Does cuff width influence the muscular adaptations accompanied by BFRresistance training? However, it should be advised to view the cuff width in relation to the quantity of the applied pressure.

\section{CONCLUSIONS}

A multitude of BFR-protocols are located in the literature with several determinants underpinning the stress responses applied to the muscle. The occlusion pressure, either given in absolute or relative values, will influence both the acute hemodynamic responses in blood flow and the muscular adaptations in response to several training sessions. No uniform pressure recommendation are identified; however, a relative pressure application offer a more controlled stimulus. Additionally, the present review highlighted the interaction of different cuff widths among BFR-protocols, revealing that a given absolute pressure could elicit different arterial occlusion responses. However, the evidence of cuff width on hypertrophy and strength adaptations are sparse, which makes it an important line of research worthy of future investigation. Although the alleged efficiency of several BFR-protocols, the current consensus allows the speculation and hypothesis acquisition that the optimal blood flow restriction protocol for maximising muscle hypertrophy and strength adaptations are yet to be elucidated. Further investigations should be conducted in an attempt to optimise the occlusion training protocol as an efficient training modality to augment force production capacity and induce muscle hypertrophy, that could be used by competitive athletes, the elderly population, and in rehabilitation clinics.

\section{SUPPORTING AGENCIES}

No funding agencies were reported by the authors.

\section{DISCLOSURE STATEMENT}

No potential conflict of interest was reported by the authors.

\section{REFERENCES}

Abe, T., Fujita, S., Nakajima, T., Sakamaki, M., Ozaki, H., Ogasawara, R., . . I Ishii, N. (2010). Effects of Low-Intensity Cycle Training with Restricted Leg Blood Flow on Thigh Muscle Volume and VO2MAX in Young Men. J Sports Sci Med, 9(3), 452-458.

Behringer, M., Behlau, D., Montag, J. C. K., McCourt, M. L., \& Mester, J. (2017). Low-Intensity Sprint Training With Blood Flow Restriction Improves 100-m Dash. J Strength Cond Res, 31(9), 2462-2472. https://doi.org/10.1519/jsc.0000000000001746

Clark, B. C., Manini, T. M., Hoffman, R. L., Williams, P. S., Guiler, M. K., Knutson, M. J., . . Kushnick, M. R. (2011). Relative safety of 4 weeks of blood flow-restricted resistance exercise in young, healthy adults. Scand J Med Sci Sports, 21(5), 653-662. https://doi.org/10.1111/j.1600-0838.2010.01100.x

Cook, S. B., LaRoche, D. P., Villa, M. R., Barile, H., \& Manini, T. M. (2017). Blood flow restricted resistance training in older adults at risk of mobility limitations. Exp Gerontol, 99, 138-145. https://doi.org/10.1016/j.exger.2017.10.004 
Counts, B. R., Dankel, S. J., Barnett, B. E., Kim, D., Mouser, J. G., Allen, K. M., . . Loenneke, J. P. (2016). Influence of relative blood flow restriction pressure on muscle activation and muscle adaptation. Muscle Nerve, 53(3), 438-445. https://doi.org/10.1002/mus.24756

Crenshaw, A. G., Hargens, A. R., Gershuni, D. H., \& Rydevik, B. (1988). Wide tourniquet cuffs more effective at lower inflation pressures. Acta Orthop Scand, 59(4), 447-451. https://doi.org/10.3109/17453678809149401

Dankel, S. J., Buckner, S. L., Counts, B. R., Jessee, M. B., Mouser, J. G., Mattocks, K. T., .. . Loenneke, J. P. (2017). The acute muscular response to two distinct blood flow restriction protocols. Physiol Int, 104(1), 64-76. https://doi.org/10.1556/2060.104.2017.1.1

Dankel, S. J., Jessee, M. B., Buckner, S. L., Mouser, J. G., Mattocks, K. T., \& Loenneke, J. P. (2017). Are higher blood flow restriction pressures more beneficial when lower loads are used? Physiol Int, 104(3), 247-257. https://doi.org/10.1556/2060.104.2017.3.2

de Oliveira, M. F., Caputo, F., Corvino, R. B., \& Denadai, B. S. (2016). Short-term lowintensity blood flow restricted interval training improves both aerobic fitness and muscle strength. Scand J Med Sci Sports, 26(9), 1017-1025. https://doi.org/10.1111/sms.12540

Goodpaster, B. H., Park, S. W., Harris, T. B., Kritchevsky, S. B., Nevitt, M., Schwartz, A. V., . . Newman, A. B. (2006). The loss of skeletal muscle strength, mass, and quality in older adults: the health, aging and body composition study. J Gerontol A Biol Sci Med Sci, 61(10), 1059-1064. https://doi.org/10.1093/gerona/61.10.1059

Graham, B., Breault, M. J., McEwen, J. A., \& McGraw, R. W. (1993). Occlusion of arterial flow in the extremities at subsystolic pressures through the use of wide tourniquet cuffs. Clin Orthop Relat $\operatorname{Res}(286), 257-261$. https://doi.org/10.1097/00003086-199301000-00038

Hylden, C., Burns, T., Stinner, D., \& Owens, J. (2015). Blood flow restriction rehabilitation for extremity weakness: a case series. J Spec Oper Med, 15(1), 50-56.

Jessee, M. B., Buckner, S. L., Dankel, S. J., Counts, B. R., Abe, T., \& Loenneke, J. P. (2016). The Influence of Cuff Width, Sex, and Race on Arterial Occlusion: Implications for Blood Flow Restriction Research. Sports Med, 46 (6), 913 - 921. https://doi.org/10.1007/s40279-016-0473-5

Kim, D., Loenneke, J. P., Ye, X., Bemben, D. A., Beck, T. W., Larson, R. D., \& Bemben, M. G. (2017). Low-load resistance training with low relative pressure produces muscular changes similar to highload resistance training. Muscle Nerve, 56(6), E126-e133. https://doi.org/10.1002/mus.25626

Laurentino, G. C., Loenneke, J. P., Teixeira, E. L., Nakajima, E., lared, W., \& Tricoli, V. (2016). The Effect of Cuff Width on Muscle Adaptations after Blood Flow Restriction Training. Med Sci Sports Exerc, 48(5), 920-925. https://doi.org/10.1249/mss.0000000000000833

Laurentino, G. C., Ugrinowitsch, C., Roschel, H., Aoki, M. S., Soares, A. G., Neves, M., Jr., . . Tricoli, V. (2012). Strength training with blood flow restriction diminishes myostatin gene expression. Med Sci Sports Exerc, 44(3), 406-412. https://doi.org/10.1249/mss.0b013e318233b4bc

lida, H., Kurano, M., Takano, H., Kubota, N., Morita, T., Meguro, K., . . Nakajima, T. (2007). Hemodynamic and neurohumoral responses to the restriction of femoral blood flow by KAATSU in healthy subjects. Eur J Appl Physiol, 100(3), 275-285. https://doi.org/10.1007/s00421-007-0430-y

Lixandrao, M. E., Ugrinowitsch, C., Berton, R., Vechin, F. C., Conceicao, M. S., Damas, F., . . Roschel, H. (2018). Magnitude of Muscle Strength and Mass Adaptations Between High-Load Resistance Training Versus Low-Load Resistance Training Associated with Blood-Flow Restriction: A Systematic Review and Meta-Analysis. Sports Med, 48(2), 361-378. https://doi.org/10.1007/s40279017-0795-y

Lixandrao, M. E., Ugrinowitsch, C., Laurentino, G., Libardi, C. A., Aihara, A. Y., Cardoso, F. N., . . Roschel, H. (2015). Effects of exercise intensity and occlusion pressure after 12 weeks of resistance 
training with blood-flow restriction. Eur J Appl Physiol, 115 (12), 2471 - 2480. https://doi.org/10.1007/s00421-015-3253-2

Loenneke, J. P., Fahs, C. A., Rossow, L. M., Sherk, V. D., Thiebaud, R. S., Abe, T., . . Bemben, M. G. (2012). Effects of cuff width on arterial occlusion: implications for blood flow restricted exercise. Eur J Appl Physiol, 112(8), 2903-2912. https://doi.org/10.1007/s00421-011-2266-8

Loenneke, J. P., Fahs, C. A., Thiebaud, R. S., Rossow, L. M., Abe, T., Ye, X., . . Bemben, M. G. (2012). The acute muscle swelling effects of blood flow restriction. Acta Physiol Hung, 99(4), 400-410. https://doi.org/10.1556/aphysiol.99.2012.4.4

Loenneke, J. P., Thiebaud, R. S., Abe, T., \& Bemben, M. G. (2014). Blood flow restriction pressure recommendations: the hormesis hypothesis. Med Hypotheses, 82(5), 623-626. https://doi.org/10.1016/j.mehy.2014.02.023

Martin-Hernandez, J., Marin, P. J., Menendez, H., Ferrero, C., Loenneke, J. P., \& Herrero, A. J. (2013). Muscular adaptations after two different volumes of blood flow-restricted training. Scand J Med Sci Sports, 23(2), e114-120. https://doi.org/10.1111/sms.12036

Mattocks, K. T., Jessee, M. B., Counts, B. R., Buckner, S. L., Grant Mouser, J., Dankel, S. J., . . . Loenneke, J. P. (2017). The effects of upper body exercise across different levels of blood flow restriction on arterial occlusion pressure and perceptual responses. Physiol Behav, 171, 181 - 186. https://doi.org/10.1016/i.physbeh.2017.01.015

Mouser, J. G., Dankel, S. J., Mattocks, K. T., Jessee, M. B., Buckner, S. L., Abe, T., \& Loenneke, J. P. (2018). Blood flow restriction and cuff width: effect on blood flow in the legs. Clin Physiol Funct Imaging. https://doi.org/10.1111/cpf.12504

Mouser, J. G., Dankel, S. J., Jessee, M. B., Mattocks, K. T., Buckner, S. L., Counts, B. R., \& Loenneke, J. P. (2017). A tale of three cuffs: the hemodynamics of blood flow restriction. Eur J Appl Physiol, 117(7), 1493-1499. https://doi.org/10.1007/s00421-017-3644-7

Navalta, James W.; Stone, Whitley J.; and Lyons, Scott (2019) "Ethical Issues Relating to Scientific Discovery in Exercise Science," International Journal of Exercise Science: Vol. 12 : Iss. 1.

Neto, G. R., Sousa, M. S., Costa, P. B., Salles, B. F., Novaes, G. S., \& Novaes, J. S. (2015). Hypotensive effects of resistance exercises with blood flow restriction. J Strength Cond Res, 29 (4), 1064 - 1070. https://doi.org/10.1519/jsc.0000000000000734

Paton, C. D., Addis, S. M., \& Taylor, L. A. (2017). The effects of muscle blood flow restriction during running training on measures of aerobic capacity and run time to exhaustion. Eur J Appl Physiol, 117(12), 2579-2585. https://doi.org/10.1007/s00421-017-3745-3

Slysz, J., Stultz, J., \& Burr, J. F. (2016). The efficacy of blood flow restricted exercise: A systematic review \& meta-analysis. J Sci Med Spor t, 19(8) , 669-675. https://doi.org/10.1016/j.jsams.2015.09.005

Vechin, F. C., Libardi, C. A., Conceicao, M. S., Damas, F. R., Lixandrao, M. E., Berton, R. P., . . . Ugrinowitsch, C. (2015). Comparisons between low-intensity resistance training with blood flow restriction and high-intensity resistance training on quadriceps muscle mass and strength in elderly. J Strength Cond Res, 29 (4), 1071 - 1076. https://doi.org/10.1519/jsc.0000000000000703

Yow, B. G., Tennent, D. J., Dowd, T. C., Loenneke, J. P., \& Owens, J. G. (2018). Blood Flow Restriction Training After Achilles Tendon Rupture. J Foot Ankle Surg. https://doi.org/10.1053/i.jfas.2017.11.008

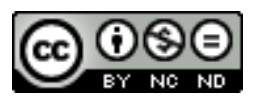

This work is licensed under a Attribution-NonCommercial-NoDerivatives 4.0 International (CC BY-NC-ND 4.0). 